\title{
Can We Afford the War on Cancer?
}

\author{
Thomas D. Szucs \\ Institute of Social- and Preventive Medicine, University of Zurich, Switzerland
}

Undoubtedly, the war on cancer is an expensive endeavour. It is estimated that, in European countries where data are available (e.g. Germany and France), cancer care accounts for a proportion of overall healthcare expenditures similar to that in the USA, i.e. approximately $5 \%$. Currently, no society can afford to provide all cancer treatments to all patients that could benefit from them. How the available resources should be allocated is one of the great and ongoing debates, and different countries approach this problem in different ways. Additionally, the more we understand the pathology, pathogenesis, diagnosis, and treatment of cancer, the more options are created. Many of these options include new diagnostic tools and more effective treatments. Obviously these innovations, paired with an increasing number of patients, lead to tremendous health care expenditures, well surpassing current budgets. Hence, the question arises how much money should be devoted to the management of neoplasms, given that resources are scarce and many other fields and specialities are competing for these resources. To address this issue it is important to know which portion of the available funds is allocated to oncological care and how efficiently this care is provided.

Hartmann and colleagues elegantly strive to give an answer to this question by analysing oncological resources and their efficiency [1]. They developed a very simple and transparent model using a macroeconomic perspective. On the basis of publicly available, official data sources they calculated oncology-related expenditures and contrasted these with the number of years of life gained between the years 2002 and 2004 in Germany. They were able to give estimates related to different disease categories and different malignancies. For example, they were able to demonstrate that the second largest contributors of life years gained were based on oncological treatment, following the treatment of injuries. Furthermore, they showed that the accrued cost per life year gained was 140,750 Euro for malignant neoplasms. This figure is more than 5 times more cost-effective than treatment for mental and behavioural disorders and more than 1.5 times more costeffective than treatment for respiratory disorders. Among the various tumour entities, digestive system cancers yielded the lowest cost-effectiveness, whereas cancers of the lip, mouth and pharynx were among the most cost-effective treatment options.

These results are impressive and illustrate the relative merit of oncological practices. However, some limitations of this analysis warrant caution. By design, this type of study may be subject to considerable confounding factors and may suffer from the ecologic fallacy. In addition, the findings may be unspecific, due to poor coding quality and possibly missing data. In order to clarify the study question, it would be useful to update the results of the study using newer data and to compare these with the present results. The introduction of new and more costly treatment options might yield significantly different values. Also, it might be useful to contrast these results with the development of general economic output.

In summary, Hartmann and co-workers should be applauded for this neat and crisp analysis. May such analyses help us to better understand where we are spending our limited resources and in which areas increased spending may be warranted.

\section{Reference}

1 Hartmann M, Kath R, Gundermann C: Oncological resource allocation in Germany. Onkologie 2008;31:85-89.

\begin{tabular}{|c|c|}
\hline KARGER & (c) 2008 S. Karger GmbH, Freiburg \\
\hline $\begin{array}{l}\text { Fax +49761 } 4520714 \\
\text { E-mail Information@Karger.de } \\
\text { www.karger.com }\end{array}$ & $\begin{array}{l}\text { Accessible online at: } \\
\text { www.karger.com/onk }\end{array}$ \\
\hline
\end{tabular}

